\title{
A Direct and Simplistic Bromination of Commercially Important Organic Compounds in Aqueous Media by Eco-friendly $\mathrm{AlBr}_{3}-\mathrm{Br}_{2}$ Reagent System
}

\author{
Sushil Kumar Sharma ${ }^{1, *}$, D. D Agarwal ${ }^{2}$ \\ ${ }^{1}$ Department of Chemistry, Shri Jagdishprasad Jhabarmal Tibrewala University, Rajasthan, India \\ ${ }^{2}$ Shri Jagdishprasad Jhabarmal Tibrewala University, Rajasthan, India
}

Copyright $(\underset{0}{2015}$ Horizon Research Publishing All rights reserved.

\begin{abstract}
A facile, simplistic, highly efficient, environmentally safe, regioselective, controllable and economical method for the bromination of organic compounds using aqueous $\mathrm{AlBr}_{3}-\mathrm{Br}_{2}$ reagent system.
\end{abstract}

Keywords Halogenation, Oxidative-Bromination, Molecular Bromine, Aqueous Medium, New Reagent System

\section{Introduction}

To date, available research on bromination of organic aromatic compounds in aqueous medium is very few and far between, except only few examples. Ganchegui et al. described the oxybromination of phenol $\left(\mathrm{C}_{6} \mathrm{H}_{5} \mathrm{OH}\right)$ and aniline $\mathrm{C}_{6} \mathrm{H}_{5} \mathrm{NH}_{2}$ subsidiary products using $\mathrm{NaBr}-\mathrm{H}_{2} \mathrm{O}_{2}$ in $\mathrm{H}_{2} \mathrm{O} / \mathrm{scCO}_{2}$ (water/supercritical carbon dioxide) biphasic system, howbeit low conversion rate, high temperature $\left(40^{\circ} \mathrm{C}\right.$ ), longer duration (from 4 to $20 \mathrm{~h}$ ) and use of surplus amount of reagent (substrate : $\mathrm{NaBr}: \mathrm{H}_{2} \mathrm{O} ; 1: 3: 3$ ) are some of the concomitant inadequacies. Furthermore, experiments using dense gases must only be conducted in appropriate equipment and under apposite safety precautions. In recent times, Padgorsek et al. defined an interesting oxidative bromination of triggered arenes using $\mathrm{H}_{2} \mathrm{O}_{2}-\mathrm{HBr}$ /"on water" system is advantageous since water is the only by-product; though, a very high reaction time (from $8 \mathrm{hr}$ to $28 \mathrm{hr}$ ) and the several threats associated with $\mathrm{H}_{2} \mathrm{O}_{2}$ make the process of limited industrial utility. The highly lethal 48 per cent aqueous $\mathrm{HBr}$ reacts aggressively with many metals with the generation of extremely flammable hydrogen gas, which may burst, which further limits its usage. Other described-on water $\|$ and -in water $\|$ brominating system are limited only to the synthesis of bromohydrins, $\alpha$-bromoketones, iodination and benzylic bromination.

Factually hundreds of Br2-based and oxidative bromination reagents have been described for the bromination of organic compounds, some latest reports are given in Table no. 5. For Bromine $\left(\mathrm{Br}_{2}\right)$ there are several other reagent systems that have been established as a substitute, but not restricted to, $\mathrm{NBS} /[\mathrm{Bmim}] \mathrm{Br}$, $\mathrm{ZrBr}_{4} /$ diazene, [k.18-crown-6] $\mathrm{Br}_{3}$, [BMPy] $\mathrm{Br}_{3}$ [Hmim] $\mathrm{Br}_{3}$, [Bmim] $\mathrm{Br}_{3}, 53 \mathrm{f}$ poly(4-vinylpyridinium tribromide), DABCO-bromine, pentypyridinium tribromide, ethylene bis(N- methylimidazolium) ditribromide. The bromination of polymer latex has been carried out using bromine emulsion which is prepared by liquefying bromine $\left(\mathrm{Br}_{2}\right)$ into an aq. solution of wetting agent/surfactant.

On the other hand, nothing like such reagent commercialized till date, because of its costly nature, very bad retrieval and recycling of used reagent/agent, waste treatment for large quantities of $\mathrm{HBr}$-byproduct and poor stability of reagents and storage challenges in long period; therefore they are suitable for laboratory-scale requirements only with narrow application range. In the Previous section of the chapter, we have described aq. $\mathrm{Al} \mathrm{Br}_{3}-\mathrm{Br}_{2}$ system in acetonitrile $(\mathrm{MeCN})$ as a highly effective brominating agent which provided a rapid bromination of industrially important compounds in outstanding yields and pureness. The method is advantageous due to the cost-effective nature of the brominating reagent and high pureness of the wanted products, whereas the usage of organic solvents acetonitrile $(\mathrm{MeCN})$ and the further utility. Consequently, to make the system more industrially-oriented and environmentally-approachable, we tried the bromination of liquid substrates using aq. $\mathrm{Al} \mathrm{Br}_{3}-\mathrm{Br}_{2}$ can diffuse through the dews of aniline leading to bromination. During the reaction process the bromine $\left(\mathrm{Br}_{2}\right)$ color vanished instantly resulting the instantaneous synthesis of 2,4,6- tribromoaniline in 96 per cent yield (HPLC pureness 99.7 per cent) within $15 \mathrm{~min}$ of reaction time (Table no. 7, entry 19). This result heartened us to brominate the solid substrate (4-nitroaniline) under the similar conditions. As we noticed an instantaneous loss of reddish-brown hue in the round bottom flask and whole $\mathrm{Br}_{2}$ 
get used within 2-3 minutes of magnificent signifying a prompt interface between the $\mathrm{Br}_{2}$ and 4-nitroaniline has occurred in the aqueous system. Yellow color crystalline powder in 98 per cent yield of 2,6-dibromo-4-nitroaniline (HPLC purity of 99.08 per cent) was achieved (Table no. 7, entry 16). Cheered by the above resulted outcomes, the bromination of industrially-important compounds using aqueous $\mathrm{Al} \mathrm{Br}_{3}-\mathrm{Br}_{2}$ solution under aqueous conditions at room temperature without using any organic solvent before and after the completion of reaction, the reaction have successfully been performed

While bromination was carried out in water using aq. Al $\mathrm{Br}_{3}$ system, it offers the following benefits:

(1) absence retrieval step and loss of solvent during the recycling procedure that makes the present reaction more appropriate, (2) no addition of water is obligatory after completion of reaction as the brominated product too is insoluble in water in case of acetonitrile solvent, $15 \mathrm{ml}$ water has to be added for $10 \mathrm{ml}$ acetonitrile $(\mathrm{MeCN})$ solvent to separate the precipitated product. This upsurges the overall volume of filtrate thereby upturn the cost of recovery of $\mathrm{Al}$ $\mathrm{Br}_{3}$ from the aq. medium at the completion of reaction, (3) the reaction is functionally-easy and friendly which don't requires heating or cooling, (4) the brominated compound and $\mathrm{Al} \mathrm{Br}_{3}$ recuperated at the end of reaction are in unadulterated form as there is no organic solvent in the reaction mixture for their adulteration and also the only $\mathrm{HBr}$ byproduct present in the aqueous filtrate has to be transformed to $\mathrm{Al} \mathrm{Br}_{3}$ (5) the present method leads to zero waste discharge to the surroundings, since from the three components of the reagent, i.e., $\mathrm{Al} \mathrm{Br}_{3}, \mathrm{Br}_{2}$ and water; one atom of $\mathrm{Br}_{2}$ was shifted to organic substrate and the other half-forming $\mathrm{HBr}$ is again employed back to $\mathrm{Al} \mathrm{Br}_{3}$ by its neutralization with $\mathrm{Ca}(\mathrm{OH})_{2}$.

The $\mathrm{Al} \mathrm{Br}_{3}$ of the fresh reaction and additional $\mathrm{Al} \mathrm{Br}_{3}$ produced from $\mathrm{HBr}$ nullification was recovered as a crystalline solid by concentrating the aqueous filtrate $(14 \mathrm{~g}$ $\mathrm{Al} \mathrm{Br}_{3}$ in $20 \mathrm{ml} \mathrm{H}_{2} \mathrm{O}$ similar to collected works procedure). The recovered $\mathrm{Al} \mathrm{Br}_{3}$ has possible industrial value in different sectors i.e; Pharmaceuticals, preservers, and fire retardants etc. have also been employed effectively to rejuvenate the brominating reagent for bromination in consequent batches without any substantial loss of reactivity. Henceforward, at the end of the reaction we have nonentity to dispose to the environment which is justified in view of green chemistry.

Bromination of substituted aromatics compounds using aqueous $\mathrm{Al} \mathrm{Br}_{3}-\mathrm{Br}_{2}$ system

\section{Objective}

Clean and green reaction methods that do not use dangerous organic solvents are reinvigorated and are in excessive demand now. A modern report on "green solvents" determined that the use of solvents like dioxane, acetonitrile, 1-butanol, propanol, acids, acetone, ethyl, formaldehyde and
THF are not suggested from an environmental viewpoint. Water, on the other hand, is an auspicious solvent because it is readily available, non-flammable, non-toxic and can give the easy split-up of catalysts or reagents from many aromatic products. To date, water is rarely used in accessible research on bromination of aromatic compounds, which is very limited except few examples. Factually hundreds of $\mathrm{Br}_{2}$-based and oxidative bromination reagents have been described for the bromination of organic compounds. On the other hand, no such commercial reagent is available till date, due to their costly nature, poor retrieval and recycling of used reagent, waste treatment for large quantities of $\mathrm{HBr}$-byproduct and poor stability of reagents and storage challenge in long periods; therefore they are suitable for laboratory-scale requirements only with narrow application range. The usage of aqueous $\mathrm{AlBr}_{3}-\mathrm{Br}_{2}$ system as the most inexpensive brominating agent and $\mathrm{H}_{2} \mathrm{O}$ as a reaction media exemplifies the most logical and reasonable choice of brominating reagent to fulfill the need of inexpensive, cleaner and most effective system. In simple words, $\mathrm{H}_{2} \mathrm{O}$ fulfills all the requirements in direct synthesis of commercially- important brominated aromatic compounds. In current study, we are presenting, for the first time, a simple and direct bromination of $\mathrm{C}_{6} \mathrm{H}_{5} \mathrm{OH}$ and $\mathrm{C}_{6} \mathrm{H}_{5} \mathrm{NH}_{2}$ subsidiary products with strong electron-withdrawing groups (EWG) such as carboxylic (-COOH), nitro $\left(-\mathrm{NO}_{2}\right)$ and formyl (-CHO) as examples of pharmaceutical reaction intermediates under absolutely aqueous conditions.

\section{Experimental}

\section{i) Reagents and analytics}

Reagents and initial material were procured from across, Aldrich and Merck and were used as usual. Only fine powdered form substrates were used during complete reaction process, granulated and scaly substrates were grinded and transformed into fine powder prior to reactions to improve the dissolution factor. Twice as distilled water was used during the complete study, Water model no. 2695 instrument with PDA detector was used for HPLC analysis purpose, column $\mathrm{C} 18(250 \mathrm{~mm} \times 4.6 \times 5 \mu)$, solvent scheme of 70 per cent $\mathrm{CH} 3 \mathrm{OH}+30$ per cent $\mathrm{H}_{2} \mathrm{O}$, and $1 \mathrm{~mL} /$ minute flow rate. HPLC purity is represented by area per cent. Bruker Avance II 400 NMR spectrometer was used for NMR studies and chemical shifts were described by $\delta$ ppm; spectra were recorded in DMSO and CDCI3, 1H NMR (comparative to TMS referenced as $0.00 \mathrm{ppm}$ ) and $13 \mathrm{C}$ NMR (comparative to DMSO referenced as $39.50 \mathrm{ppm}$ ). GCMS studies were performed by using "Agilent GC-5893" with chemstation software; HP5-MS-column, with specification $30 \mathrm{~m} \times 0.25 \mathrm{~mm} \times 0.25 \mu$; constant flow of- $2 \mathrm{ml} /$ minutes; mass-director; mass range- 14 to $650 \mathrm{amu}$; detector temp$290^{\circ} \mathrm{C}$; injector temp- $280^{\circ} \mathrm{C}$; injected sample volume- 1 microliter of 5 per cent solution in methanol. Mass spectroscopical (MS) data were documented on "Micromass Quattro Micro API triple quadrupole MS" which was 
equipped with a ordinary APCI ion source. Infrared spectra studies were carried out on a Shimadzu Prestize 21 FT-IR Instrument $\left(\mathrm{KBr}, 3400-430 \mathrm{~cm}^{-1}\right)$. Isolated compounds were acknowledged on the basis of physical determination and spectroscopic data (13C NMR, 1H NMR, Infrared and Mass Spectroscopy).

ii) A typical synthesis path of 2, 6-dibromo-4-nitroaniline (16)

A solution was prepared using $\mathrm{AlBr}_{3}(3.95 \mathrm{~g}, 20 \mathrm{mmol})$ in aqueous media $(10 \mathrm{ml})$ and was added to $\mathrm{Br}_{2}(3.25 \mathrm{~g}, 20$ $\mathrm{mmol}$ ), the resultant mixture was stirred continuously at room temperature till it give clear dark pale yellow solution. Immediately this solution was added to a fine powdered form of 4-nitroaniline (1.3733 g, $10 \mathrm{mmol})$ booked in a round-bottom flask (100 ml capacity) equipped with a magnetic stirrer using a pressure-equalizing funnel within 2 -3 minutes of time. The bromine color vanished immediately and 2,6-dibromo-4-nitroaniline was achieved (yellowish thick precipitates) within 20 minutes (Monitored by Thin Layer Chromatography) at room temperature. The filtration of precipitated mass was done by vacuum filtration method using Bunchner funnel, and then washed-off with $\mathrm{Na}_{2} \mathrm{~S}_{2} \mathrm{O}_{3}$ solution and dehydrated in oven at $100^{\circ} \mathrm{C}$. The filtrate was saved for the Later runs. The product was achieved as yellow powder $(2.90 \mathrm{~g}, 98$ per cent yield, and 99.03 per cent HPLC area pureness). Melting point: $206^{\circ} \mathrm{C}$ (literature, $23 \mathrm{~b}$ 206-208 ${ }^{\circ}$ ). $1 \mathrm{H} \mathrm{NMR} \mathrm{(400} \mathrm{MHz,} \mathrm{DMSO):} \delta$ value 8.25 (s, $2 \mathrm{H}, \mathrm{ArH}), 6.85$ (s, 2H, NH 2 ); 13C NMR (100 MHz, DMSO): 144.36, 135.69, 122.49, 109.44; IR (KBr): 3450, 3366, 3184, 2798, 2659, 2363, 1642, 1515, 1488, 1348, 1298, 1270, 1154, $953,879,816,747,669,584,543,464 \mathrm{~cm}-1$; MS, Atmospheric Pressure Chemical Ionization (APCI) $\mathrm{m} / \mathrm{z}$ (mass-to-charge ratio) called for $\mathrm{C}_{6} \mathrm{H}_{4} \mathrm{Br}_{2} \mathrm{~N}_{2} \mathrm{O}_{2}$ :295.9; found 295.2.

iii) Procedure for recycling of Hydrogen Bromide as AlBr3 and reformation of brominating reagent (Recycle 1)

The neutralization of filtrate originated from above reaction done by $\mathrm{Al}(\mathrm{OH})_{3}(0.7401 \mathrm{~g}, 10 \mathrm{mmol})$ to convert hydrogen bromide into $\mathrm{AlBr}_{3}$. Consequently, $(3.23 \mathrm{~g}, 20$ mmol) $\mathrm{Br}_{2}$ was added to the aq. solution containing recycled aluminium tribromide solution was then added fine powder of 4-nitroaniline (1.3813 g, $10 \mathrm{mmol})$ quickly within 5 minutes taken in a round-bottom flask $(100 \mathrm{ml})$ equipped with a pressure-equalizing funnel and magnetic stirring bar. The thick yellowish precipitates of 2, 6dibromo-4-nitroaniline were attained within 20 minutes at room temperature immediately after adding $\mathrm{Br} 2$ color disappeared. By using vacuum filtration the end product was separated from the mother liquor (solution left over after crystallization) and then washed-off with sodium thiosulfate $\left(\mathrm{Na}_{2} \mathrm{~S}_{2} \mathrm{O}_{3}\right)$ solution $(10$ per cent, $10 \mathrm{ml} \times 3)$ and dried out in vacuum drying oven at $100^{\circ} \mathrm{C}$. A high purity (99 per cent) 2 , 6-dibromo-4-nitroaniline yellow powder was achieved in $2.82 \mathrm{~g}$ ( 98.08 per cent) yield with melting point $206^{\circ} \mathrm{C}$. The distinguishing data was documented for the isolated product and found similar as given in the above distinctive method.
The hydrogen bromide evolved was again nullified and the aqueous solution was uninterruptedly recycled in the next run with an additional amount of $\mathrm{Br}_{2}$.

\section{iv) The Route for Recycle/Reutilize 2,3 and 4}

Analogous to the above typical method of Reutilize $1, \mathrm{Br}_{2}$ ( $3.2 \mathrm{~g}, 20 \mathrm{mmol})$ was added to the aq. solution containing recycled aluminium tribromide $\left(\mathrm{AlBr}_{3}\right)$ achieved after the separation of 2, 6-dibromo-4-nitroaniline $\left(\mathrm{Br}_{2} \mathrm{C}_{6} \mathrm{H}_{2}\left(\mathrm{NO}_{2}\right) \mathrm{NH}_{2}\right)$ and the reaction proceeded in a similar reaction pattern with 4- nitroaniline, $\mathrm{C}_{6} \mathrm{H}_{6} \mathrm{~N}_{2} \mathrm{O}_{2}$ $(1.3726 \mathrm{~g}, 10 \mathrm{mmol})$ for every reaction cycle.

\section{Result \& Discussion}

\section{i) Reaction conditions screening}

The dibromination of para-substituted substrate decreases the possible complex mixture of mono- and dibrominated species, thus in order to abridge the analytics, 4- nitroaniline 16 (4-NA) was castoff as a typical substrate in a first-screening in a first- screening for appropriate reaction conditions. To optimize the yield and pureness, the bromine $\left(\mathrm{Br}_{2}\right)$ and $\left(\mathrm{AlBr}_{3}\right)$ concentration effects on the end product yield and $\mathrm{Mp}$ of 2, 6-dibromo-4- nitroaniline (DBNA) were studied in the dibromination of 4-NA.

\section{ii) The effect on yield and melting point of DBNA by mole ration of $\mathrm{Br}_{2}$}

The excellence of the end product is strongly reliant on the mole ratio of $\mathrm{Br}_{2} / 4-\mathrm{NA}$ which also has been confirmed by recent studies. It also been initiated that the optimal yield ( 98 per cent) of 2, 6-dibromo-4- nitroaniline (DBNA) and the desired melting point of $206^{\circ} \mathrm{C}$ (literature, $206-208^{\circ} \mathrm{C}$ ) are achieved at 2:1 mole ratio of $\mathrm{Br}_{2} / 4-\mathrm{NA}$ in the bromination of 4-NA by aqueous $\mathrm{AlBr}_{3}-\mathrm{Br}_{2}$ solution as a effective brominating agent. Further, if we increase the mole ratio of $\mathrm{Br}_{2} / 4$ - NA from 2.0 to 2.2 , yield of end product becomes stagnant. If we reduce the mole ratio from 2.0 to 1.8 , the end product yield drops $98-93$ per cent with a reduction in melting point $198-200{ }^{\circ} \mathrm{C}$, which is not actually as per the required specifications. Further reduction in mole ratio of $\mathrm{Br}_{2} / 4$ - NA from 1.8 to 1.65 , decrease the yield percentage of under-brominated product from 93-88 per cent, which melts at $160-170^{\circ} \mathrm{C}$. The monobrominated 4-nitroaniline were achieved that melt at $102^{\circ} \mathrm{C}$ and $100-101^{\circ} \mathrm{C}$, correspondingly (melting point of 2-bromo-4-nitroaniline is $104^{\circ} \mathrm{C}$ ), at the mole ratio of 1.5 and 1.25 .

iii) Influence of $\mathrm{AlBr}_{3}-\mathrm{Br}_{2}$ mole ratio on yield and melting point of 2, 6-dibromo-4- nitroaniline (DBNA)

Available literature shows an identical pattern in the bromination of 4-NA using aqueous $\mathrm{AlBr} 3$ solution as brominating agent because of increase in mole ratio of $\mathrm{AlBr}_{3} / 4-\mathrm{NA}$ from 0.25 -2.0; at mole ratio 2:1 ideal yield and preferred melting point are achieved. With increase in mole ratio of AlBr3/4-NA from 0.25 to 2.0, melting point does not change significantly but the yield of the product upturns 
from 91 to 98 per cent. The function of aluminium tribromide $\left(\mathrm{AlBr}_{3}\right)$ was defensible by performing a blank reaction for $1 \mathrm{~h}$ at $25^{\circ} \mathrm{C}$ using molecular bromine as a brominating agent which resulted in a composite fusion of under- brominated species that melt from 160 to $190^{\circ} \mathrm{C}$. Thus, the result drawn in to conclusion that the optimal mole ratio 1:2:2 of 4-NA to $\mathrm{AlBr}_{3}$ to $\mathrm{Br}_{2}$ was establish to be best for the dibromination of 4-NA.

\section{iv) Stirring}

For mixing the hydrophobic aromatic substrate with the aqueous inorganic medium and for preventing local high concentrations of active bromo species, as the reaction was prompt, a proficient/effective stirring (750 rpm or higher) was required. The common applicability of this method was recognized when bromination of structurally-different activated aromatic compounds substituted with electron-withdrawing groups were analyzed (Table 2). It is the revolution of the present bromination reagent (aq. $\mathrm{AlBr}_{3}-\mathrm{Br}_{2}$ solution) over a newly reported brominating system (NBS/[Bmim]Br or dioxane) that $\mathrm{C}_{6} \mathrm{H}_{5} \mathrm{OH}$ and $\mathrm{C}_{6} \mathrm{H}_{5} \mathrm{NH}_{2}$ byproducts with strong electron-withdrawing groups (EWG) such as $-\mathrm{COOH},-\mathrm{NO}_{2}$ and $-\mathrm{CHO}$ were promptly brominated regioselectively in outstanding yields and pureness. The same reported system, however, yields a combination mix of mono- and dibromo products. In the present system, salicylic acid 1 and 4-hydroxybenzoic acid 2 were transformed with quantitative conversion resulting in clean synthesis of 3,5- dibromosalicylic acid (92 per cent yield; 96.2 per cent HPLC purity) and 3,5-dibromo-4hydroxybenzoic acid (94 per cent yield; 99.2 per cent HPLC purity) after $20 \mathrm{~min}$ and $15 \mathrm{~min}$, respectively. Pharmaceutically-important aromatic aldehydes (Table 3, entries 3, 4, 5) were also instantaneously synthesized using aq. $\mathrm{AlBr}_{3}-\mathrm{Br}_{2}$ system in excellent yields. Under these conditions, acetaniline 6 and benzaniline 7 were regioselectively transformed to their mono-brominated products in very good yields. The regioselectivity witnessed in these reactions matches to that predictable for an electrophilic bromination path modulated by steric effects. We observed that oxine (8) and sulfanilamide (9) could also be efficiently brominated affording pharmaceutically-important 5, 7-dibromooxine (96 per cent yield; 99.67 per cent HPLC pureness) and 3,5-dibromosulfanilamide (94 per cent yield; 96.6per cent HPLC pureness) within 15 minutes. Another antibacterial compound, 2, 4-dibromo-6- nitrophenol was isolated in excellent yield within 20 minutes from 2-nitrophenol (Table no. 6 , entry 10$)$. With the poor reactivity 4-nitrophenol (11) shows outstanding reactivity resulting 2,6-dibromo-4-nitrophenol (94 per cent yield; 97.5 per cent HPLC pureness) within 30 minutes using two equivalent of reagent. Bromination of the same substrate with $\mathrm{H}_{2} \mathrm{O}_{2}-\mathrm{HBr}$ /'on water, gave 2, 6-dibromo-4-nitrophenol over a period of $24 \mathrm{hr}$. The advantages of the present system is an regioselective, effective, facilie, and fast bromination of deactivated anilines (Table no. 6, entries 12 to 16) in outstanding end product yields at $25^{\circ} \mathrm{C}$ upon simple admixing with aq. $\mathrm{CaBr}_{2}-\mathrm{Br}_{2}$ solution which is slightly challenging by other methodologies. 1-Bromo-2- naphthol 17 (92 per cent yield; 96.2 per cent HPLC pureness) was promptly obtained under undistinguishable reaction conditions in excellent yield within 10 minutes of reaction time while for 1,6- dibromo-2-naphthol 18 (97 per cent yield; 96.5 per cent HPLC pureness), within 25 minutes and 2 equivalents of aqueous $\mathrm{AlBr}_{3}-\mathrm{Br}_{2}$ solution were necessary. Which represents the position of the electrophilic attack and the number of inflowing $\mathrm{Br}_{2}$ atoms during reaction process can be structured by controlling the ratio of substrate: aqueous $\mathrm{AlBr}_{3}-\mathrm{Br}_{2}$ solution, i.e., 1/1 mono-, 1/2 for di-, and $1 / 3$ for tribromination of aromatic compounds. 
Table 1. A comparison of the results of present system (aq. $\mathrm{AlBr}_{3}-\mathrm{Br}_{2}$ solution) with the literature precedents of some recently published brominating systems in the synthesis of pharmaceutical intermediates

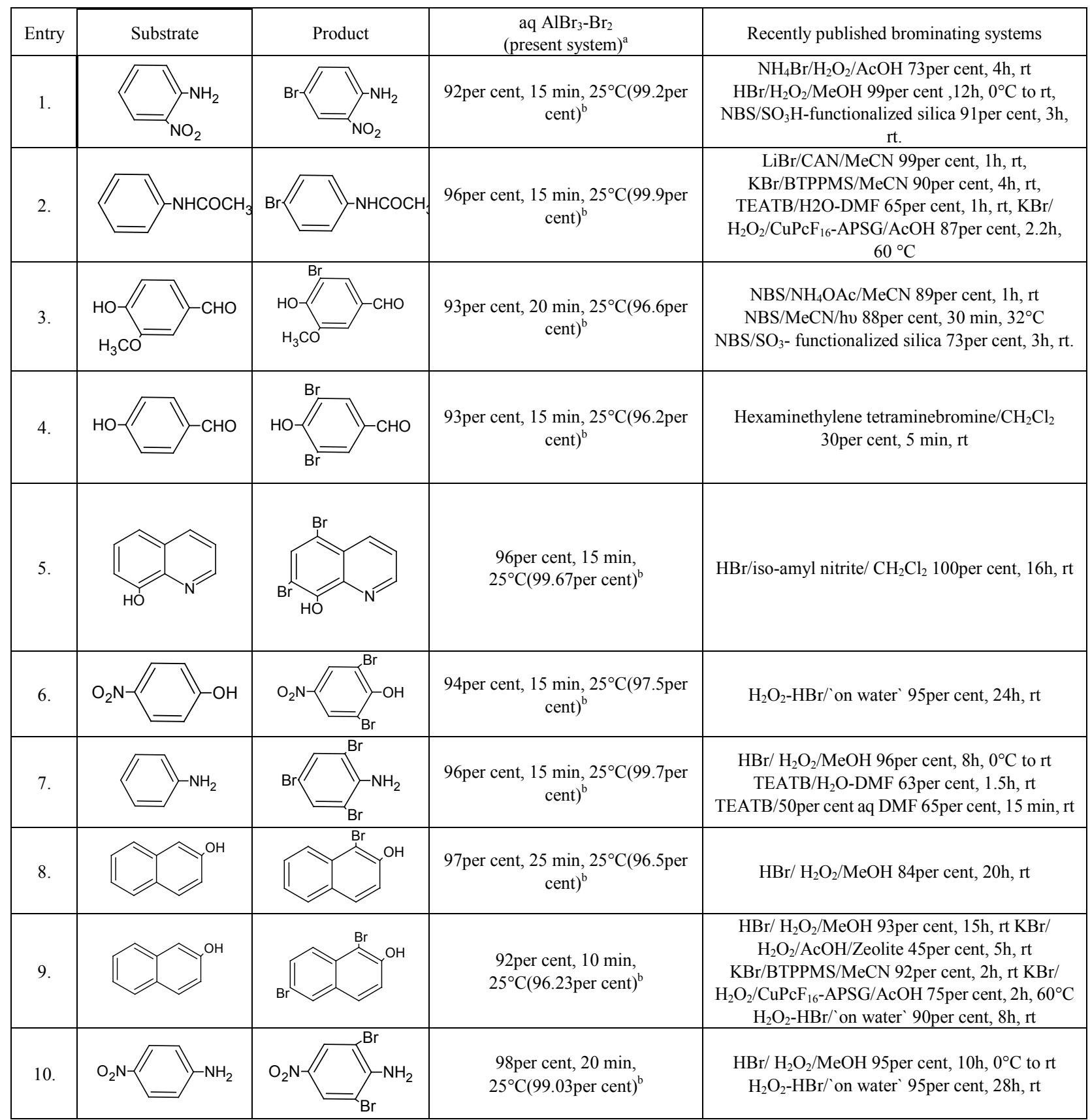

The use of aqueous $\mathrm{AlBr}_{3}-\mathrm{Br}_{2}$ system as the most economical brominating agent and $\mathrm{H}_{2} \mathrm{O}$ as a solvent/reaction medium denotes the most logical choice as a brominating reagent to fulfill the need of inexpensive, cleaner and most effective system for the instantaneous synthesis of commercially-significant brominated compounds. A comparative study of the brominating capability of the aqueous $\mathrm{AlBr}_{3}-\mathrm{Br}_{2}$ system with the recently circulated methods is testified in Table 5 which clearly indicates the benefits of the present system over obtainable methods. In this present study, we are presenting, an effective reagent system for electron-withdrawing groups (EWG) like; - $\mathrm{COOH}, \mathrm{NO}_{2}$ and $-\mathrm{CHO}$ as examples of pharmaceutical reaction intermediates under purely aqueous conditions. 
Table 2. Bromination by using aqueous $\mathrm{AlBr}_{3}-\mathrm{Br}_{2}$ system for several aromatic compounds<smiles>[X]c1cccc([Y])c1</smiles>

\begin{tabular}{|c|c|c|c|c|c|c|c|c|}
\hline \multirow{3}{*}{ Entry } & \multirow{3}{*}{ Substrate } & \multirow{3}{*}{ Product } & \multicolumn{4}{|c|}{ Solvent system } & \multirow{3}{*}{$\mathrm{Mp} /{ }^{\circ} \mathrm{C}$ (lit.) } & \multirow{3}{*}{ Application } \\
\hline & & & \multicolumn{2}{|c|}{ Water $^{\mathrm{a}}$} & \multicolumn{2}{|c|}{ Acetonitrile $^{b}$} & & \\
\hline & & & $\begin{array}{l}\text { Time } \\
/ \mathrm{min}\end{array}$ & $\begin{array}{c}\begin{array}{c}\text { Yield }^{\mathrm{c}} \\
\text { (per cent) }\end{array} \\
\text { (1) }\end{array}$ & $\begin{array}{l}\text { Time } \\
/ \mathrm{min}\end{array}$ & $\begin{array}{c}\text { Yield }^{\circ} \\
\text { (per cent) }\end{array}$ & & \\
\hline 1. & & & 20 & 96 & 25 & 97 & $\begin{array}{c}103-104 \\
(105-107)\end{array}$ & $\begin{array}{l}\text { Antibacterial, } \\
\text { antifungal }\end{array}$ \\
\hline 2. & & & 15 & 93 & 10 & 96 & 83-84 (84) & $\begin{array}{c}\text { Antibacterial, } \\
\text { antifungal and } \\
\text { anthelmintic }\end{array}$ \\
\hline 3. & & & 18 & 95 & 08 & 96 & $\begin{array}{c}120 \\
(120-121)\end{array}$ & $\begin{array}{l}\text { Intermediate for } \\
\text { agrochemical-s } \\
\text { and } \\
\text { pharmaceuticals }\end{array}$ \\
\hline 4. & & & 20 & 93 & 20 & 94 & $104(102-104$ & $\begin{array}{l}\text { Intermediate for } \\
\text { dyestuffs }\end{array}$ \\
\hline 5. & & & 20 & 98 & 10 & 98 & $206(206-208$ & $\begin{array}{c}\text { A potent } \\
\text { antifungal, in the } \\
\text { preparation of } \\
\text { diazonium }\end{array}$ \\
\hline 6. & & & 18 & 91 & 15 & 90 & $108(110-113$ & $\begin{array}{l}\text { Fine organic and } \\
\text { custom } \\
\text { intermediate }\end{array}$ \\
\hline 7. & & & 18 & 96 & 15 & 96 & $127(128-129$ & $\begin{array}{c}\text { Fine organic and } \\
\text { custom } \\
\text { intermediate }\end{array}$ \\
\hline 8. & & & 15 & 96 & 15 & 95 & 101(101-103 & $\begin{array}{l}\text { Precursor for } \\
\text { substituted } \\
\text { thiazoles used as } \\
\text { fungicides }\end{array}$ \\
\hline 9. & & & 30 & 94 & 28 & 95 & $145(145-147$ & $\begin{array}{l}\text { Pharmaceutic-al } \\
\text { intermediate }\end{array}$ \\
\hline 10. & & & 18 & 91 & 25 & 96 & $114(116-117$ & Anthelmintic \\
\hline
\end{tabular}




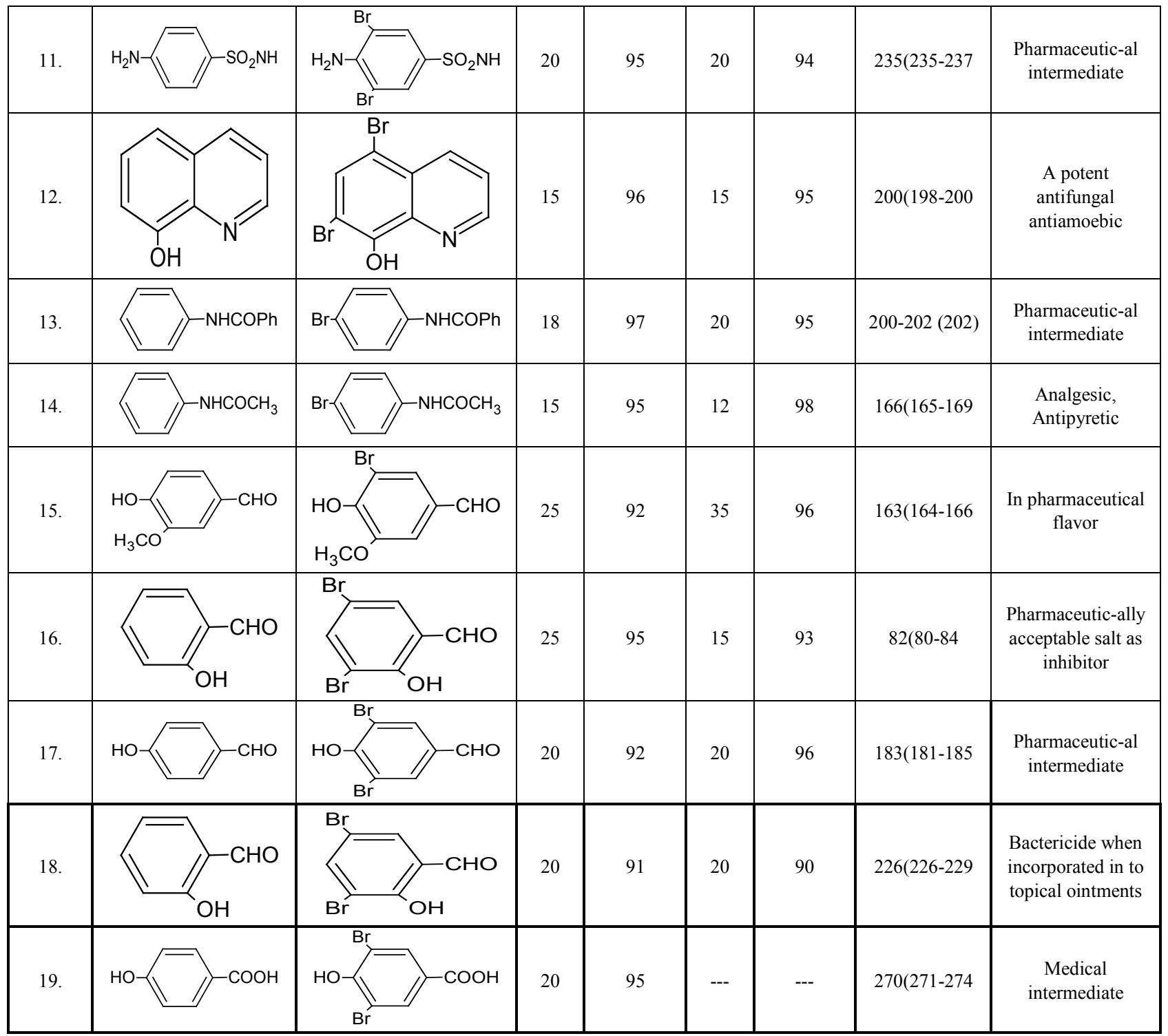

Underneath these reaction conditions, the deactivated substrate like nitrobenzene and benzoic acid did not show any transformation at all. Table no. 2 discloses that the yield and the reaction time for several brominated products are comparable in $\mathrm{H}_{2} \mathrm{O}$ and acetonitrile (ACN) as solvents, correspondingly. The only limitation associated with the reaction using water as a solvent is that granular and scaly substrates have to be crushed and ground proceeding to reactions to convert them into fine powders. Since the reaction operates entirely in water and generates absolute zero discharge; it seems very effective valuable from environmental safety point of view to extend this system for other commercially-important compounds. Subsequent, a desireable greener approach to the present study is following by an environmental friendly recycling procedure. The nonexistence of organic waste and organic solvents in the reaction process supported simple separation procedure comprised of filtration of solid phase brominated compounds and the addition of calcium hydroxide powdered form
$\left(\mathrm{Ca}(\mathrm{OH})_{2}\right)$ to the filtrate for the nutralization of hydrogen bromide waste so that the bromine of hydrogen bromide thus fixed as Aluminum bromide. The aqueous filtrate was reclaimed in the next cycle and the reinforced brominating agent was then used to brominate the substrate successively in the next run.

Table 3. Reprocessing experiments for the dibromination of 4-nitroanilinea

\begin{tabular}{|c|c|c|c|c|}
\hline Recycle & Appearance & Yield $^{\mathbf{b}}(\mathbf{p e r}$ & $\mathbf{M p}{ }^{\circ} \mathbf{C}(\mathbf{l i t} .$, & Purity $^{\mathbf{c}}$ \\
\hline Newbatch & Yellow Powder & 98.2 & 206 & 99.20 \\
\hline Reprocess 1 & Yellow Powder & 98.0 & 206 & 98.98 \\
\hline Reprocess 2 & Yellow Powder & 97.6 & $204-206$ & 98.57 \\
\hline Reprocess 3 & Yellow Powder & 97.3 & $205-206$ & 98.26 \\
\hline Reprocess 4 & Yellow Powder & 97.4 & $204-206$ & 98.84 \\
\hline
\end{tabular}

a Surroundings: 10mmol4-NA,20mmolBr2(4-NAandBr2 moles charged in every reaction cycle)and $20 \mathrm{mmolAlBr}_{3}$ (charged for fresh batch only)at room temperature $\left(25^{\circ} \mathrm{C}\right)$ for 20 minutes (each cycle).

${ }^{b}$ Inaccessible Yields $\quad c_{\text {Pureness determined by HPLC }}$ 
By this methodology, very productively and effectively the dibromination of 4-nitroaniline has been carried out for 4 cycles after the fresh batch using 4-NA: $\mathrm{Br}_{2}(1: 2)$ mole ratio in each run without adding of the fresh aluminium tribromide $\left(\mathrm{AlBr}_{3}\right)$ to give 2, 6-dibromo-4-nitroaniline within 20 minutes at room temperature. Reprocessing experiments (Table no. 7) shows that for at least 4 cycles followed by the fresh batch, there is no substantial loss of reactivity of the rejuvenated brominating reagent. When the concentration of aluminium tribromide $\left(\mathrm{AlBr}_{3}\right)$ upturns in the filtrate, then through vaporization process filtrate was concentrated which causes precipitation of $\mathrm{AlBr}_{3}$ as a crystalline solid and an added amount of $\mathrm{AlBr}_{3}(7 \mathrm{~mol})$ was recuperated after fresh batch +4 cycles: resulted 1 mol of aluminium tribromide $\left(\mathrm{AlBr}_{3}\right)$ produced likewise in every cycle by the neutralization of hydrogen bromide by adding $\mathrm{Al}(\mathrm{OH})_{3}$. Therefore, starting with $1 \mathrm{~mol}$ of 4-NA wrt $2 \mathrm{~mol}$ of Aluminium tribromide in the fresh batch, At the end of reaction process we achieved $7 \mathrm{~mol}$ of $\mathrm{AlBr}_{3}$. Consequently, effectively the byproduct hydrogen bromide has been utilized, and at the end of reaction, process generates zero discharge of organic waste and effluent to the surroundings.

\section{Characterization of Representative Brominated Compounds:}

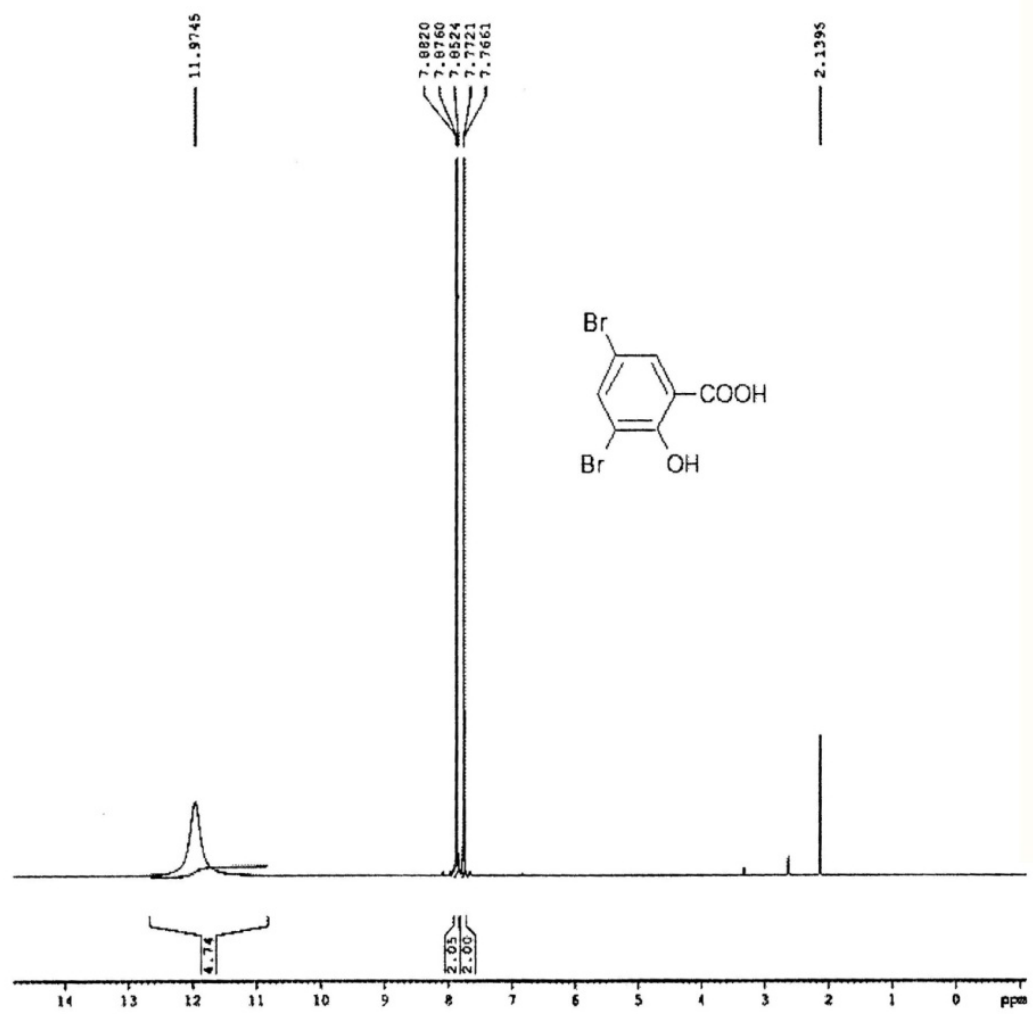

Figure 8. 1H -NMR spectra of 3,5-dibromosalicylic acid (1) 


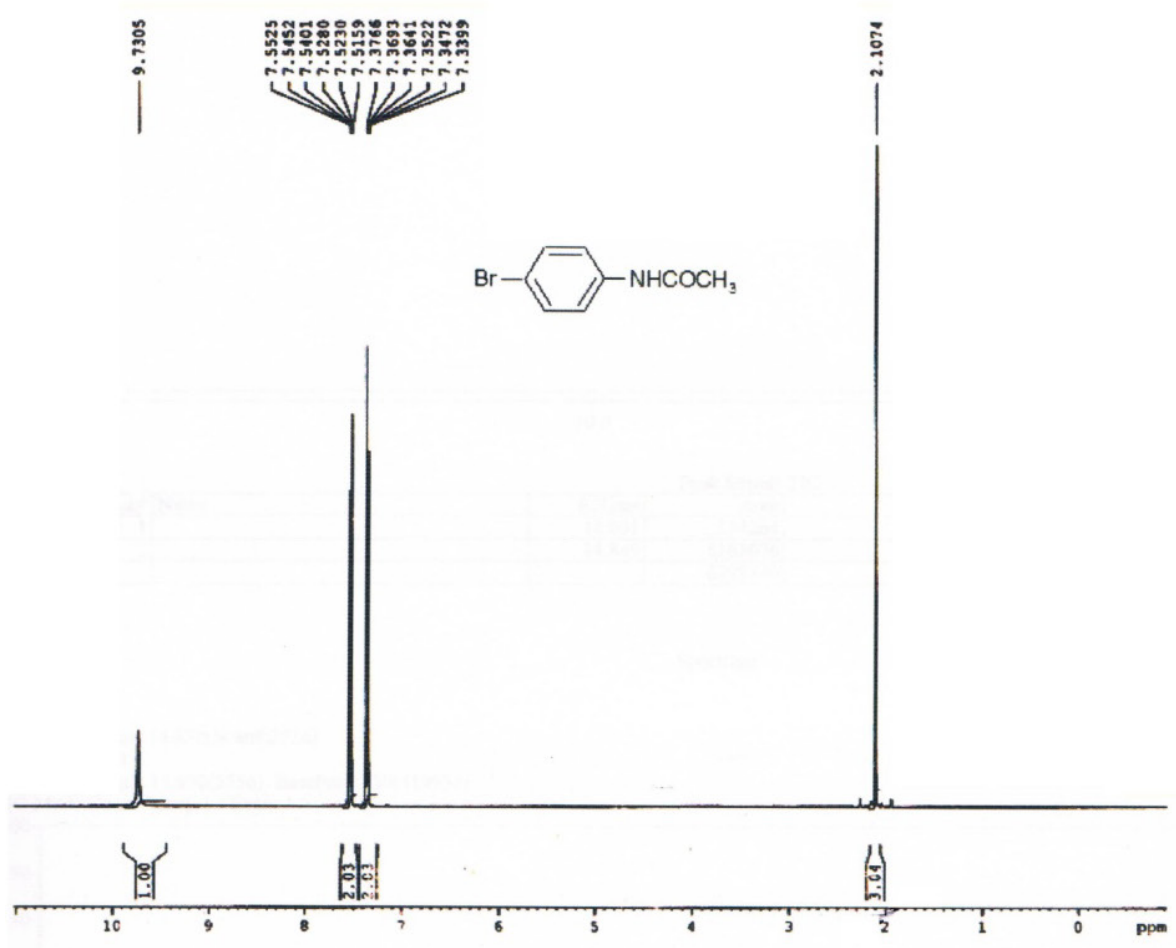

Figure $\quad{ }^{1}$ H-NMR spectra of 4-bromoacetanilide (6)

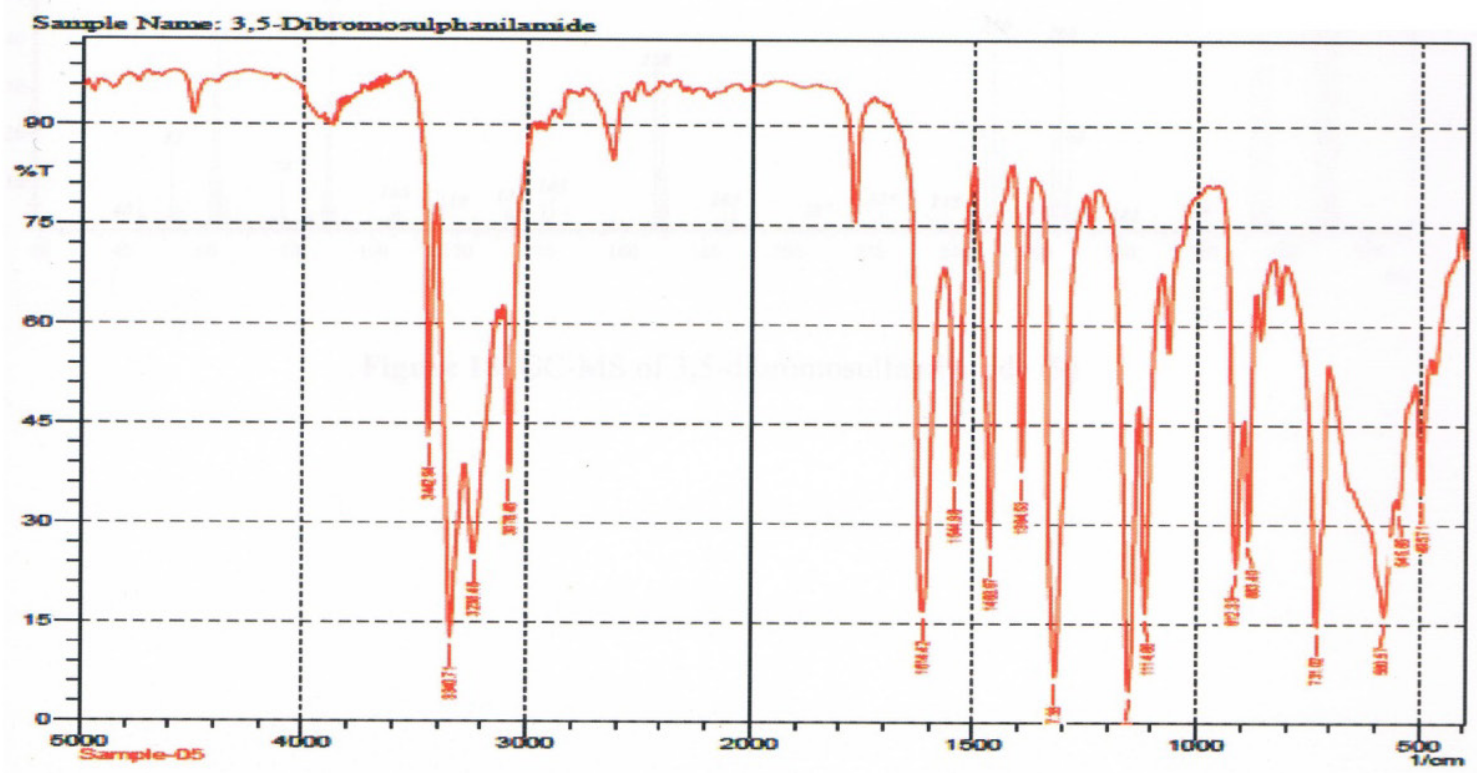

Figure 9. IR spectra of 3,5-dibromosulfanilamide (9) 

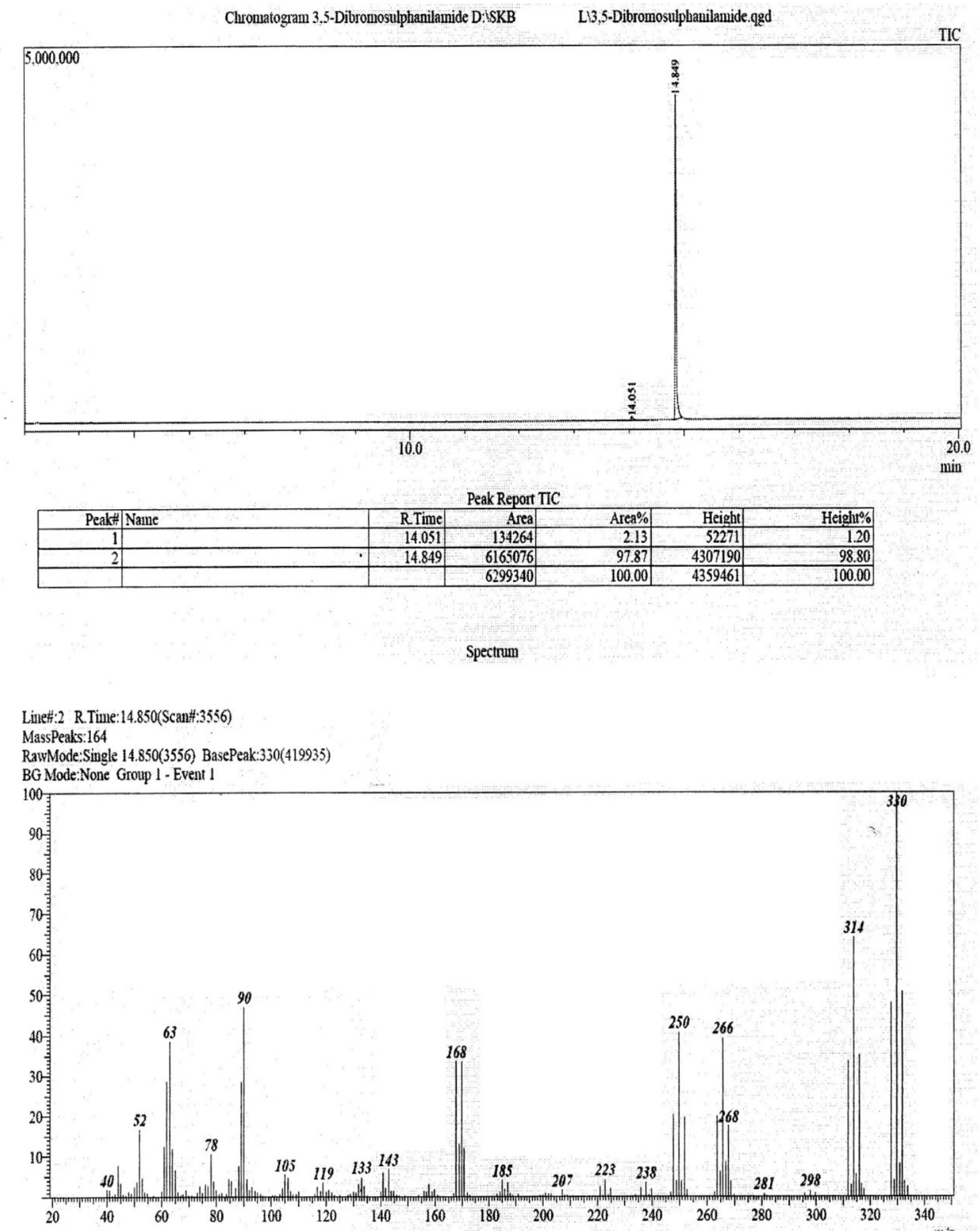

Figure 10. GC-MS of 3,5-dibromosulfanilamide (9) 


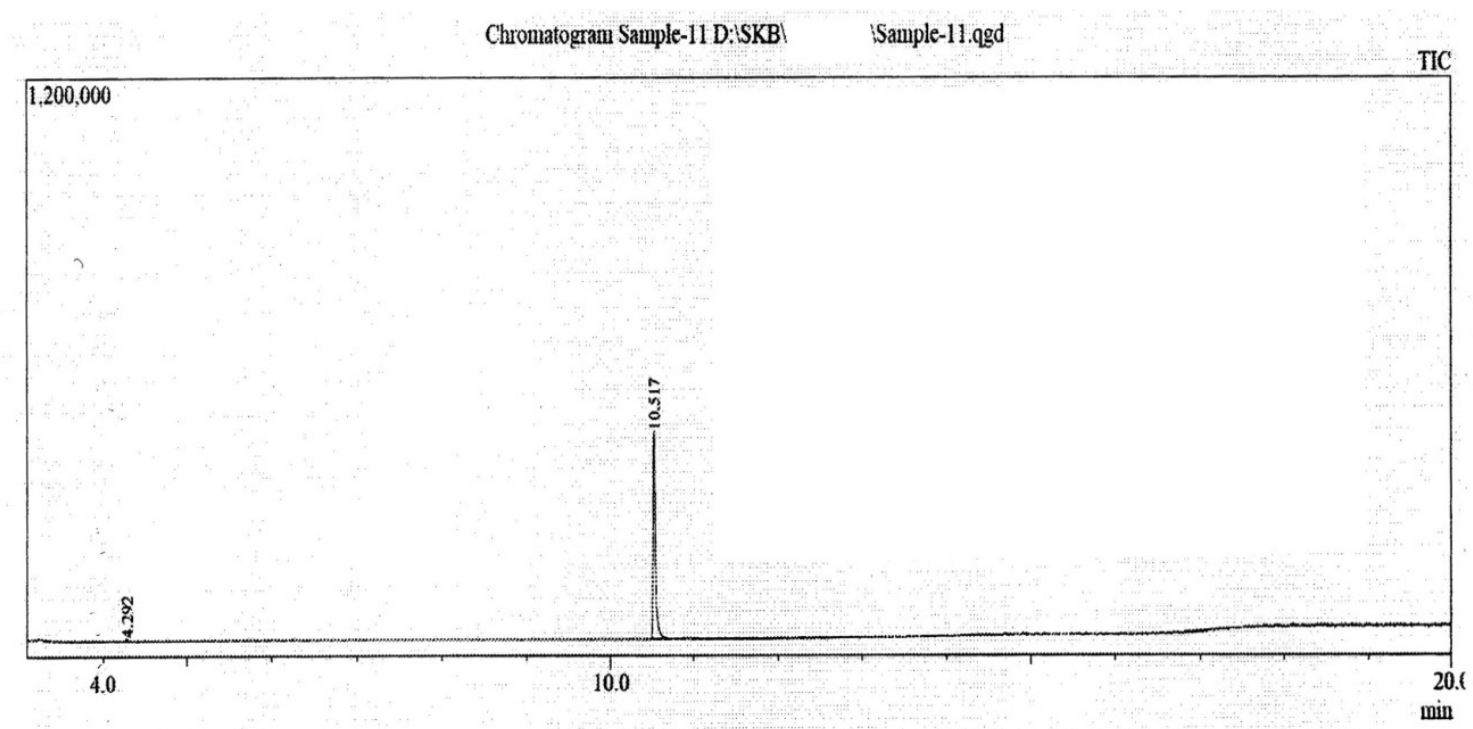

Peak Report TIC

\begin{tabular}{|c|c|c|c|c|c|c|}
\hline Peakt & Name & R.Time & Area & Area\% & Height & Height\% \\
\hline & DISULFIDE, DIOCTYL & 4.292 & 8476 & 1.02 & 6711 & 1.49 \\
\hline & & 10.517 & 826275 & 98.98 & 442822 & 98.51 \\
\hline & & & 834751 & 100.00 & 449533 & 100.00 \\
\hline
\end{tabular}

Spectrum

Line\#:2 R.Time: 10.517(Scan\#:2256)

MassPeaks:77

RawMode:Averaged 10.513-10.520(2255-2257) BasePeak:297(60688)

BG Mode:Calc. from Peak Group 1 - Event 1

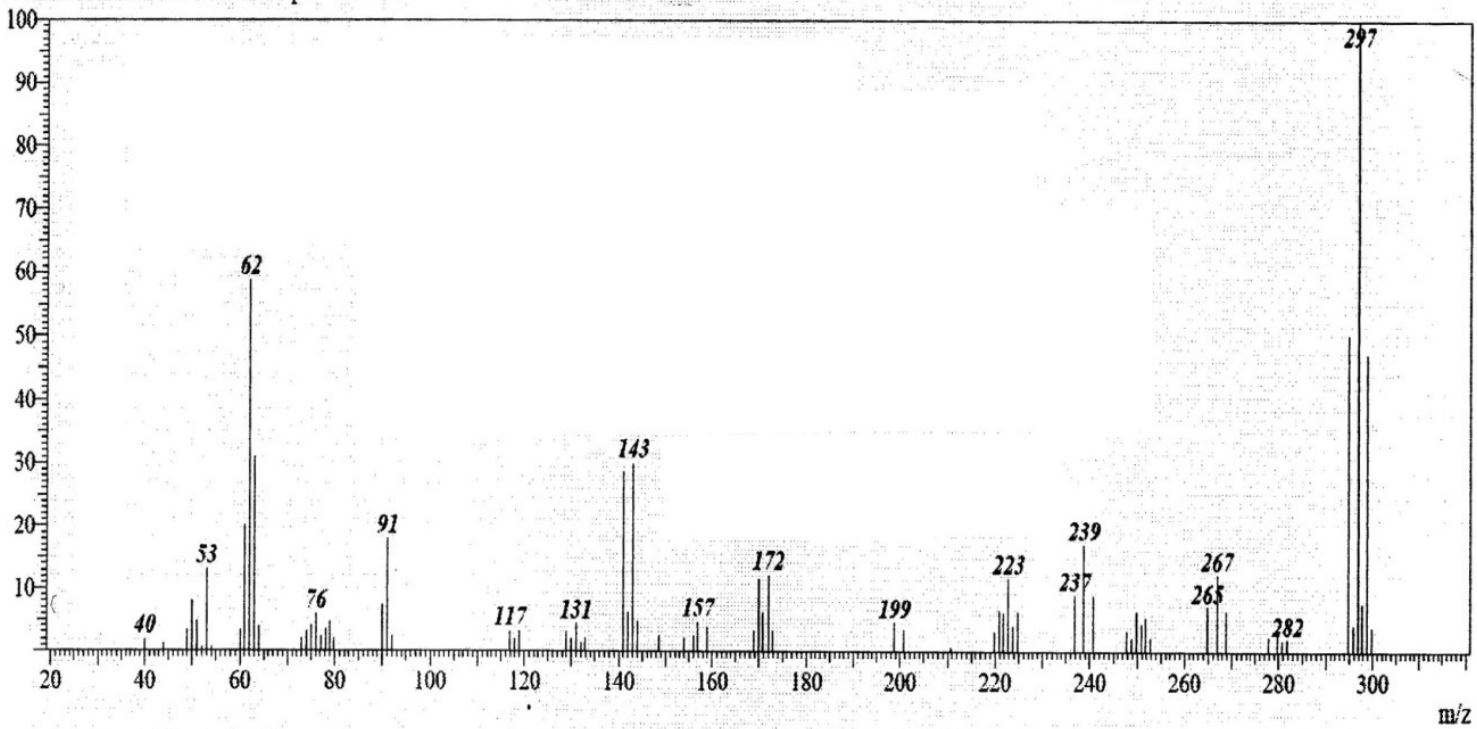

Figure 11. GC-MS of 2,4-dibromo-6-nitrophenol (10) 

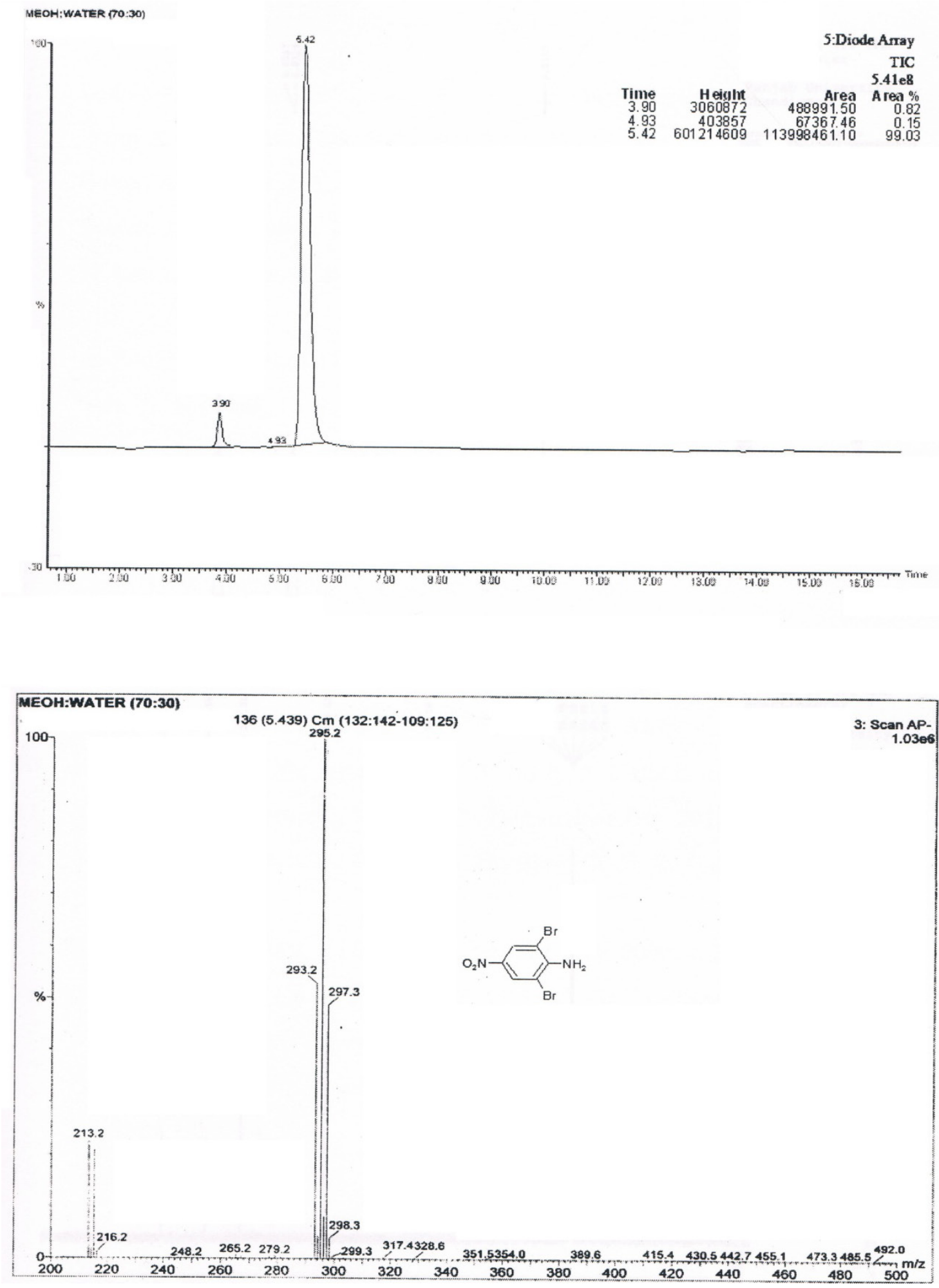

Figure 12.LC/MS of 2,6-dibromo-4-nitroaniline (Br2C6H2(NO2)NH2) (16) 

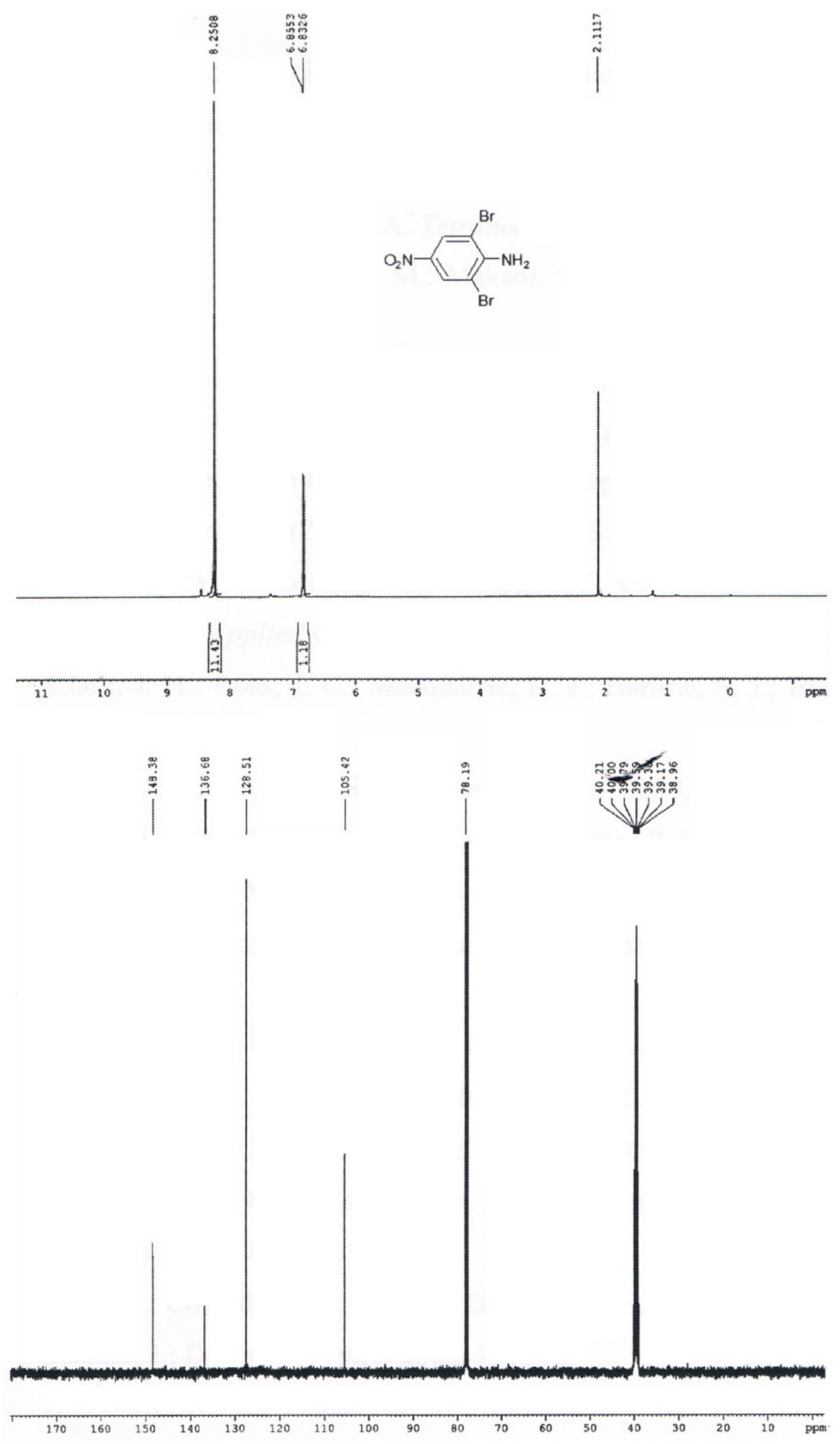

Figure 13. 1H and 13C-NMR of 2,6-dibromo-4-nitroaniline (16) 


\section{Conclusions}

We have testified a rapid, mild, cost effective and facile method for the effective and selective synthesis of pharmaceutically-important brominated intermediates using aq. $\mathrm{AlBr}_{3}-\mathrm{Br}_{2}$ system as an instantaneous brominating agent under aqueous conditions. The green features of this practice include no use of organic solvent and an operative utilization of $\mathrm{HBr}$ byproduct which lead to zero organic waste and zero waste discharge to the environment, consequently applicable for large scale bromination.

The categorization data (1H NMR, Infrared and Mass Spectroscopy) achieved for various representative compounds are given below:

3,5-Dibromo-4-hydroxybenzoic acid (2): White fine crystalline powder; 1H NMR $(400 \mathrm{MHz}$, Dimethyl Sulfoxide"DMSO"): $\delta 8.02$ (2H, ArH, s), $11(1 \mathrm{H}, \mathrm{OH}, \mathrm{s}), 13$ $(1 \mathrm{H}, \mathrm{COOH}, \mathrm{s})$; Infrared (KBr): 3450, 3081, 2976, 2652, 2530, 1798, 1690, 1588, 1482, 1420, 1404, 1340, 1305, 1275, $1205,1169,1137,903,893,766,738,718,671,520,470$ $\mathrm{cm}-1 ; \mathrm{MS} \mathrm{m} / \mathrm{z}$ (mass-to-charge ratio) calcd. for $\mathrm{C} 7 \mathrm{H} 4 \mathrm{Br} 2 \mathrm{O} 3$ : 295.9 , found 295.

5-Bromovanillin (5): Slightly-brown powder; IR ( $\mathrm{KBr})$ : $3318,3103,3074,3009$,

2976, 2943, 2851, 2746, 1725, 1592, 1502, 1464, 1448, $1425,1355,1293,1192$,

$1148,1047,973,855,796,681,602,592,538,527 \mathrm{~cm}-1$; $\mathrm{MS} \mathrm{m} / \mathrm{z}$ (mass-to-charge ratio) calcd. For C8H7BrO3: 231, found 235 .

4-Bromoacetanilide (6): White crystals, 1H NMR (400 MHz, Dimethyl Sulfoxide"DMSO”): $\delta 2.1$ (s, 3H, CH3), 7.41 (d, J = 2.96 Hz, 2H, Ar), 7.64 (d, j= $2.89 \mathrm{~Hz}, 2 \mathrm{H}, \mathrm{Ar}$ ), 9.71 (s, 1H, NH). IR (Potassium Bromide): 3288, 3261, 3157, $3128,3045,1684,1656,1594,1576,1544,1478,1388,1312$, 1280, 1246, 1002, 845, 824, 754, 678, $508 \mathrm{~cm}-1$. MS Atmospheric Pressure Chemical Ionization (APCI) $\mathrm{m} / \mathrm{z}$ (mass-to-charge ratio) calcd. For C8H8BrNO: 216.07, found 216.

5,7-Dibromo-8-hydroxuquinoline (8): Light buff colored powder; 1H NMR (400 MHz, Trichlorodeuteromethane "CDCl3"): $\delta$ value $7.446(\mathrm{~d}, \mathrm{~J}=0.514 \mathrm{~Hz}, 1 \mathrm{H}), 8.465$ (ddd, J $=8.803, \mathrm{~J}=1.836, \mathrm{~J}=0.514 \mathrm{~Hz}, 1 \mathrm{H}), 7.223(\mathrm{dd}, \mathrm{J}=8.778$,

$\mathrm{J}=4.681 \mathrm{~Hz}, 1 \mathrm{H}), 8.839(\mathrm{dd}, \mathrm{J}=4.687, \mathrm{~J}=1.834 \mathrm{~Hz}, 1 \mathrm{H})$. IR (KBr): 3087, 1742, 1576, 1489, 1464, 1387, 1374, 1266, 1212, 1156, 1043, 947, 884, 815, 782, 736, 672, 643, 614, 589, 559, $500 \mathrm{~cm}-1 . \mathrm{MS}$ Atmospheric Pressure Chemical Ionization (APCI) $\mathrm{m} / \mathrm{z}$ (mass-to-charge ratio) calcd. For C9H5Br2NO: 302.95 , found 302.2.

3,5-Dibromosulphanilamide (9): Shining-white crystalline powder; 1H NMR $(400 \mathrm{MHz}$, Trichlorodeuteromethane "CDCl3"): $\delta: 5.74(2 \mathrm{H}, \mathrm{s}, \mathrm{NH} 2)$, 6.76 (s, 2H, SO2NH2), 7.92 (s, 2H, Ar); IR (KBr): 3443, $3341,3238,3076,1614,1545,1464,1395,1317,1151,1114$, 912, 883, 731, 580, 546, $496 \mathrm{~cm}-1$; MS Atmospheric Pressure Chemical Ionization (APCI) $\mathrm{m} / \mathrm{z}$ (mass-to-charge ratio) calcd. for $\mathrm{C} 6 \mathrm{H} 6 \mathrm{Br} 2 \mathrm{~N} 2 \mathrm{O} 2 \mathrm{~S}: 330$, found 330.

2,4,6-Tribromoaniline (19): Shining white fine needles;
1H NMR (400 MHz, Trichlorodeuteromethane "CDCl3"): $\delta$ : 7.5 (2H, s, Ar), 4.54 (2H, br. S, NH2). Infrared (KBr): 3436, $3288,1468,1392,1274,1238,1057,849,736,712,666,542$, $478 \mathrm{~cm}-1$ MS Atmospheric Pressure Chemical Ionization (APCI) $\mathrm{m} / \mathrm{z}$ (mass-to-charge ratio) calcd. for $\mathrm{C} 6 \mathrm{H} 4 \mathrm{Br} 3 \mathrm{~N}$ : 329.816, found 328.8 .

\section{REFERENCES}

[1] De la Mare, P. B. Electrophilic Halogenation: Reaction Pathway Involving Attack by Electrophilic Halogens on Unsaturated Compounds, Cambridge University Press, Cambridge, UK, (1976), Chapter 5. (b) Taylor, R. Electrophilic Aromatic Substitution, Wiley, Chichester, UK ,(1990).

[2] a) Ganchegui, B.; Leitner, w. Green Chemistry (2007), 9, 26. (b) Podgorsek, A.; Stavber, S.; Zupan, M.; Iskra, Journal Tetrahendron (2009), 65, 4429.

[3] Pingali, S. R. K.; Madhav, M.; Jursic, B.S. Tetrahendron Letters. (2010), 51, 1383.

[4] a) Surine, W. R.; Majewski, T.E. Preparation of 3,5-dibromosalicylic acid. U.S. Patent 3,381,032, (1968). (b) Hai, T.T.; Nelson, D.J. Phamaceutical grade 3,5-dibromosalicylic acid and method for synthesizing same. U.S. Patent 5,013,866, (1991).

[5] (a) Bedekar, A. V.; Gadde, R.; Ghosh, P. K. Process for preparing 2,4,4,6-tetrabromo-2, 5-cycloyhexadienone. U.S. Patent 6,838,582, (2005). (b) De La Mare, P. B. D. Electrophilic Halogenation: Reaction Pathway Inoving Attack by Electrophilic Halogens on Unsaturated Compounds; Cambridge University Press: London.

[6] (a) The Merck Index, 13th edition, An Encyclopedia of Chemicals, Drugs, and Biologicals, Merck and Co. Inc., Whitehouse Station, NJ, 2001. (b) Aldrich Handbook of Fine Chemical Company, Inc.: Wisconsin, USA, (1990).

[7] Adimurthy, S.; Ramachandraiah, G.; Bedekar, A.V.; Ghosh, S.; Ranu, B.C.; and Ghosh, P.K.; (2006).Eco-friendly and versatile brominating reagent prepared from a liquid bromine precursor. Green Chemistry, 8, 916-922|917.

[8] Zolfigol, M.A.; Chehardoli, G.; Salehzadesh, S.; Adams, H.' Ward, M. D. Tetrahendron Letters, (2007), 48, 7969.

[9] Hosseinzadeh, R.; Tajbakhsh, M.; Mohadjerani, M.; Lasemi, Z. Syntesis. Communication, (2010), 40, 868.

[10] AI-Zoubi, R.M.; Hall, D.Organic Letters (2010), 12, 2480

[11] Beckmann, J.; Bolsinger, J.; Duthie, A.; and Finke, P.; (2013). Diarylhalotelluronium(IV) cations [(8-Me2NC10H6)2TeX]+ $(\mathrm{X}=\mathrm{Cl}, \mathrm{Br}, \mathrm{I})$ stabilized by intramolecularly coordinating N-donor substituents. Dalton Trans. 10.1039.

[12] Chiappe, C.; Leandri, E.; Pieraccini, D. Chemistry Commun. (2004), 2536.

[13] Beckmann, J.; Bolsinger, J.; Duthie, A.; and Finke, P.; (2013). Diarylhalotelluronium (IV) cations

[(8-Me2NC10H6)2TeX]+ $(\mathrm{X}=\mathrm{Cl}, \mathrm{Br}, \mathrm{I})$ stabilized by intramolecularly coordinating N-donor substituents. Dalton Trans.10.1039. 
[14] Benitez, F. J.; Acero, J.L.; Real, F.J.; Roldan, G. and Casas, F. (2011). Bromination of selected pharmaceuticals in water matrices. Chemosphere. 85: 1430-1437.

[15] Borikar, S.P.; Daniel, T.; Paul, V. Tetrahedron Letters. (2009),50,1007.

[16] Chinnagolla, R.K.; Pimparkar, S.; and Jeganmohan, M.; (2013). Ruthenium-catalyzed intramolecular selective halogenation of O-methylbenzohydroximoyl halides: a new route to halogenated aromatic nitriles. Chem. Commun., 49, 3146-3148.

[17] Ceska, G. W. Aqueous bromine emulsions. U.S. Patent 3,886,081, (1975). Chaudhuri, M. K.; Khan, A. T.; Patel, B. K. Tetrahedron Letters. (1998), 39, 8163.

[18] Chiu, Y. (Denville, NJ); Cottrell, S.A. (Baton Rouge, LA); Tung, H. S. (Getzville, NY); 'Kopkalli, H.(Staten Island, NY) and Cerri, G.(Parsippany, NJ). (2011). Process for the Manufacture of Fluorinated Olefins. U.S. Class: 570/175; Serial No.: 402,372.

[19] Chiappe, C.; Leandri,; Pieraccini, D. Chem. Commun. (2004), 2536.

[20] Chinnagolla, R.K.; Pimparkar, S.; and Jeganmohan, M.; (2013). Ruthenium- catalyzed intramolecular selective halogenation of O-methylbenzohydroximoyl halides: A new route to halogenated aromatic nitriles. Chem. Communications, 49, 3146-3148.

[21] Sharma, S.; Agarwal, D. D.; (2014). NH4Br-Br2 catalyzed oxidative bromination of aromatic compounds. Journal of Agriculture and Life Sciences. Vol. 1, No. 1; 65-81.

[22] Sharma, S.; Agarwal, D. D.; (2014). Oxidative Chlorination of aromatic compounds in aqueous media. Journal of Agriculture and Life Sciences. Vol. 1, No. 1; 146-164.

[23] D Sharma, S.; Agarwal, D. D.; (2014). Molybdate catalyzed oxidative bromination of aromatic compounds using mineral acids and $\mathrm{H} 2 \mathrm{O} 2$. International Journal of scientific and research publications. Vol. 4, Issue 6; 01-12.

[24] Das, B.; Venkateswarlu, K.; Mahji, A.; Siddaiah, V.; Reddy, K. R. J. Molecular Catalysis A: Chemical (2007), 267, 30. Del Valle, C. J. Method of producing calcium bromide. U.S. Patent 4, 234, 556, 1980.

[25] Deshmukh, A.P.; Pandiya, K. J.; Jadhav, V.K.; and Salunkhe, M.M.; (1998). Halogenation of Aromatic Compounds by using Sodium Perborate as an Oxidant. Journal of Chemical Research (S), 828-829.

[26] Do, H.Q.; Daugulis, O.; (2008). A Simple Base-Mediated Halogenationof Acidic sp2 C-H Bonds under Noncryogenic Conditions. Organic Letters, Vol.11, No. 2, 421-423.

[27] Eberlin, A.; Williams, D.L.H.; (2002). Halogenation of enol tautomers of 2- cyanoacetamide and malonamic acid. Journal of Chem. Soc., Perkin Transactions. 2, 1316-1319.

[28] Edwards; Jeffrey, D.; Palermo; John. Analgesic and anti-inflammatory composition. U.S. Patent 7,510,732, (2009).

[29] Fong, H.L.(Sugar Land, TX); Johnson, T.H.(Houston, TX ) andSemple, T.C.(Friendswood,TX).(2009). Conversion of Alkylhalides in to Alcohol Alkoxylates. Current U.S. Class: 568/671. Serial No.: 887194.

[30] Forsyth; Adam, B.; Pryor; Ernest, D.; McGarry; James, E.; Harney; Gerald, D. W. Compositions containing certain 2,4-halo-6nitrophenols or derivatives thereof and methods for using same to eradicate internal parasites in warm- blooded animals. U.S. Patent 4,031,249, 1977.

[31] Gavara, L.; Boisse, T.; Riogo, B.; Henichart, J. P. Tetrahedron-SD (2008), 64, 4999.III, D. W.; Eaves Jr., C. C.; Haynes Jr., J. F. Annals of Emergency Medicine 1989, 18, 778 .

[32] Gerhard, H.; Phillips; Gray, W; Pratt; John, K.; Srouji; Gabriel, H. Substituted thiazoles and their use as fungicides. U.S. Patent 5,045,554, (1991).

[33] Gershin, H.; Parmegiani, R.; Godfrey, P.K. Antimic. Agents Chemotherapy (1972), 1, 373.

[34] Gershon, H.; McNeil, M. W.; Parmegiani, R.; Godfrey, P. K. Applied Microbiology (1971), 22, 438.

[35] Gnaim, J. M.; Sheldon, R. A. Tetrahedron Letters. (2005), 46, 4465.

[36] Hai, T. T.; Nelson, D. J. Pharmaceutical grade 3,5-dibromosalicylic acid and method for synthesizing same. U.S. Patent 5, 013, 866, (1991).

[37] Hajipour, A.R.; Pourmousavi, S.A. and Ruoho, A.E. (2006). 1-Benzyl 4-

aza-1-azoniabicyclo[2.2.2] OctanetribromideasaRegenerablea ndUseful Reagent for Bromination of Phenols under Mild Conditions. Ind. Journal of Chem. 45B (Mar): 796-800. 